\title{
Other HPV Typing Method
}

National Cancer Institute

\section{Source}

National Cancer Institute. Other HPV Typing Method. NCI Thesaurus. Code C159820.

An indication that the method used to perform human papillomavirus (HPV) genotyping was identified in the study but is not present in the form. 